УДК 33

DOI $10.21661 / \mathrm{r}-472977$

\title{
И.С. Эпов
}

\section{ИСТОРИЯ ВОЗНИКНОВЕНИЯ ГЦС}

Аннотация: на сегодняшний день глобальные цепочки стоимости стали одним из ключевых элементов мировой экономики, которая наиболее четко отражает тенденции глобализаџии и транснационализации. ГЦС стали главным инструментом для углубления прочессов глобализаџии в современной мировой экономике и вовлечения развивающихся стран кмеждународному производству, торговле. Страны стали конкурировать между собой за определенную роль и место в цепочках стоимости. В статье будет рассмотрен прочесс эволюиии, теоретические подходы и предпосылки возникновения глобальных иеепочек стоимости.

Ключевые слова: глобальные цеепочки добавленной стоимости, ГЦС, предпосылки, глобализация, международный аутсорсинг.

\section{I.S. Epov}

\section{HISTORY OF GLOBAL VALUE CHAINS ORIGIN}

Abstract: nowadays, global value chains have become one of the key elements of the world economy, which most clearly reflects the trends of globalization and transnationalization. The global value chains have become the main tool for globalization progress in the modern world economy and involving developing countries in international production and trade process. Countries began to compete among themselves for a certain role and place in the cost chains. In the article will be considered evolution process, theoretical approaches and preconditions of emergence of global value chains.

Keywords: global value chains, GVC, preconditions, globalization, international outsourcing. 
Первыми попытками использования аутсорсинга стал западный опыт по передаче вопросов по разработке и внедрению информационных технологий специализированным фирмам в 70-х годах XX века. Сделано это было в целях сокращения издержек; так как стоимость процесса неуклонно возрастала. Затем стал постепенно реализовываться аутсорсинг финансовых подразделений, подразделений по организации питания и уборке помещений, транспортных подразделений и т. д. Способствовал этому и масштабный рост индивидуального предпринимательства в сфере услуг в 80-90е годы [4].

Международный (внешний) аутсорсинг впервые был применен в США в 80-е годы XX века. Этому в изрядной мере поспособствовало неблагоприятное экономическое положение страны - период стагфляции. По определению стагфляцией называется ситуация, в которой экономический спад и депрессивное состояние экономики (стагнация и рост безработицы) сочетаются с ростом цен - инфляцией. Предпринятые Федеральным Резервным Банком меры по улучшению экономического состояния страны привели к тому, что в 1981 г. последовал резкий рост курса доллара, превышающий 4 немецкие марки и 360 японских йен за один доллар (при нормальном курсе около 120 йен/доллар). Американская промышленность оказалась в затруднительном положении, а зарубежные компании получили возможность держать цены на прежнем уровне при гарантированном ценовом превосходстве.

Оказавшись зажатыми между сильным долларом и все возрастающей конкуренцией из-за рубежа, американские автопроизводители попали в практически безвыходную ситуацию. Им пришлось прибегнуть к радикальным мерам, чтобы остаться на плаву. В итоге капитализм отреагировал замедлением темпов технического прогресса. От более высокой производительности труда мировая промышленность в целом перешла к более низкой производительности, но использующую большое количество живого труда. Произошел перенос производства в регионы с низкой оплаты труда, и General Motors стад первой компанией, передавшей свое производство в Мексику, закрыв 10 заводов в Флинт Мичигане (США). 
Данная тенденция продолжилась и ускорилась после подписания договора NAFTA между США, Мексикой и Канадой. Chrysler, General Motors и Ford сначала перевели, а потом и расширили свои производственные мощности в Мексике, а их примеру вскоре ста-ли следовать и другие компании, Американские и японские фирмы-производители электроники, такие как Toshiba, Motorola и Texas Instruments, перенесли большинство своих производственных мощностей в страны с дешевой рабочей силой, такие как Тайвань и Сингапур, которые, помимо прочего, отличались благоприятным инвестиционным режимом.

По данным исследования Industry Week Census on Manufacturing, 54,9\% aмериканских компаний используют аутсорсинг в производстве и 43,8\% - в обслуживании оборудования. При этом большинство из них используют именно международный аутсорсинг. Так, в настоящее время корпорация Ford две трети комплектующих и услуг заказывает на стороне - при полностью самостоятельном выпуске комплектующих и автомобилей в первые годы после своего основания. По данным ВТО, еще в 1998 г. лишь 37\% стоимости выпускаемых в США автомобилей производилось на родине: $30 \%$ стоимости автомобилей приходилось на сборку машин в Южной Корее; 17,5\% стоимости - на покупку комплектующих и современных технологий в Японии; 7,5\% - на дизайн, осуществлявшийся в Германии; 4\% - на производство мелких деталей в Тайване и Сингапуре; 2,5\% - на рекламу и маркетинг(Великобритания); $1,5 \%$ - на обработку данных (Ирландия и Барбадос). Также и многие компьютерные компании перешли к стопроцентному производственному аутсорсингу [4].

Таким образом, аутсорсинг производственных / промышленных процессов, став отправной точкой в истории возникновения механизма формирования глобальных цепочек стоимости, положил начало массовому распространению данного феномена в бизнес-практике многих западных предприятий.

На графике ниже мы можем проследить рост прямых иностранных инвестиций в развивающиеся и переходные экономики. Довольно резкий скачок приходится на период с 80-х годов, когда как пик инвестиций приходится на предкризисный период в 2007 году. 


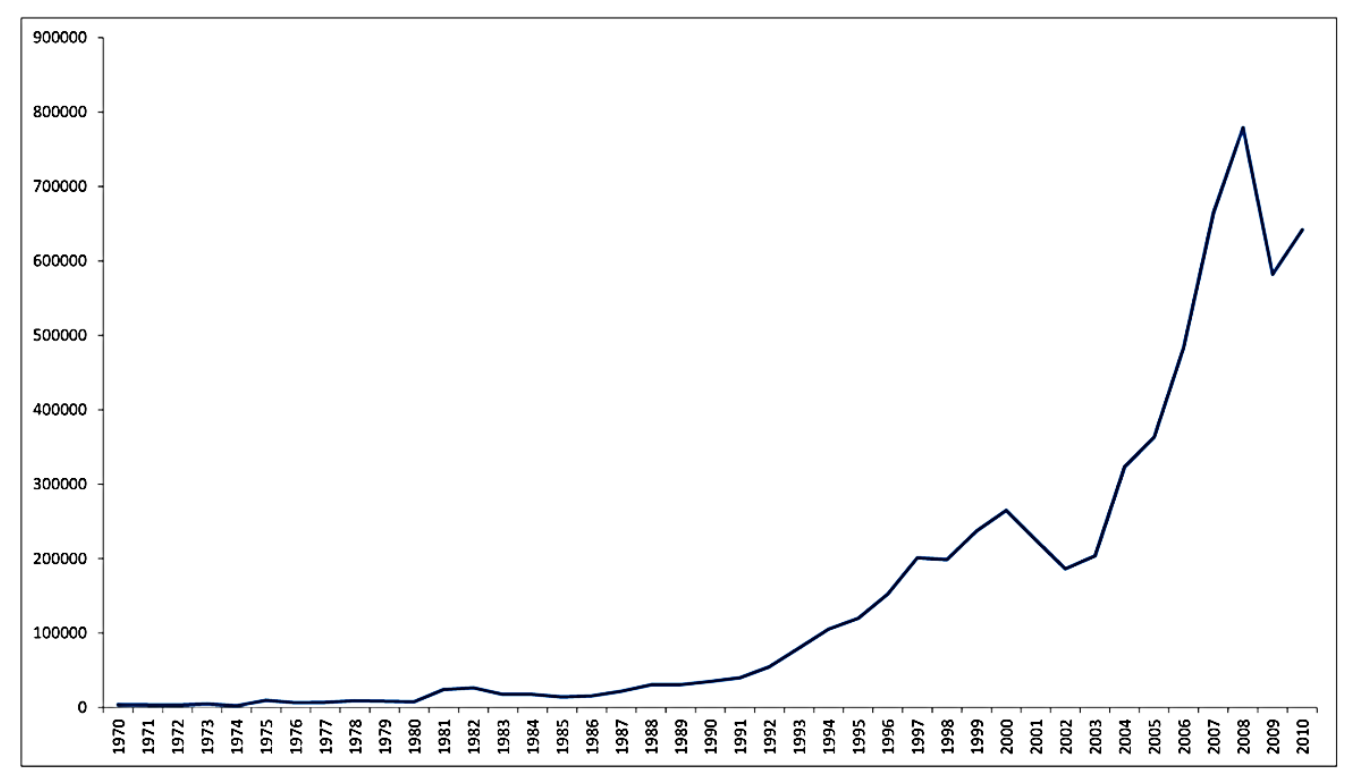

Рис. 1. Доля прямых иностранных инвестиций в развивающиеся и переходные экономики в 1970-2010гг. (в млн долл. США по текущему валютному курсу) [3]

Этот феномен объясняется экспертами тем, что после краха Советского Союза и распада социалистической системы зона безопасности для западных инвестиций в мире резко возросла. Это было связано со многими факторами:

1. Национально-освободительное движение было ослаблено.

2. Движение социалистической ориентации практически прекратилось.

3. Правительств, ведомых левыми коммунистами и рабочими по всему миру, стало мало.

4. А также угроза национализации собственности транснациональных корпораций резко снизилась.

5. Все эти факторы привели к тому, что огромное число инвесторов были вовлечены в этот процесс, результат которого и отражен на графике.

Конечно же, самым важным шагом для роста ТНК было сотрудничество с развивающимися странами, что и формировало механизм образования ГЦС [1].

Сам термин ГЦС был создан и введен в оборот в 1985г. профессором М. Портером в своей книге «Конкурентное преимущество». Профессор Колумбийской бизнес-школы Брюс Когут определил, что механизм начисления стоимости есть процесс, при котором взаимодействуют все технологии с ресурсами 
капитала, труда, преобразовывая первичные ресурсы в конечный продукт, подлежащему дальнейшему сбыту на рынке. В данном случае компания становится в большей степени вертикально интегрированной, либо зачастую занимает только одно звено в этом процессе [3].

Говоря о ГЦС, страны и компании могут располагаться на начальных, промежуточных или конечных стадиях в цепочке добавлен-ной стоимости в зависимости от их специализации, и их позиция с течением времени может меняться. Первые добывают природные ресурсы, производят сырье или интеллектуальные активы (НИОКР, проектирование, дизайн), в то время как вторые осуществляют производство деталей, компонентов и узлов, а последние - специализируются на сборке и/или дистрибуции, маркетинге и брендинге продукции, а также на работе с клиентами. При этом создание стоимости в условиях цепочек неравномерно распределено между различными мероприятиями. Наибольшая добавленная стоимость, как правило, создается при производстве ключевых компонентов или в сфере услуг (НИОКР, дизайн, маркетинг, брендинг, сбыт продукции, обслуживание клиентов).

Причиной, по которой многие страны с периферийной экономикой становятся участниками глобальных цепочек стоимости, является возможность выйти на рынки развитых капиталистических стран. Это становится реальным только при вступлении в сотрудничество с крупными транснациональными корпорациями, которое подразумевает под собой выполнение всех условий сотрудничества и предложение более качественного и дешевого выполнения всех обязательств.

Цепочки добавленной стоимости неоднородны для различных отраслей промышленности, предприятий, товаров или услуг. Некоторые части цепочек придерживаются классической конвейерной структуры, когда продукт или услуга подвергаются последовательной обработке, в то время как другие включают финальную сборку нескольких промежуточных товаров или услуг.

Наиболее глобальный характер цепочки добавленной стоимости получили в производстве транспортного оборудования и электронной промышленности. Для данных отраслей характерна максимальная доля иностранной 
(реэкспортированной) добавленной стоимости в валовом экспорте (37-38\%); они предполагают длинные и сложные цепочки, поскольку многие детали и узлы могут быть легко произведены по отдельности, транспортированы на большие расстояния, а сборка конечной продукции может быть вынесена в свободные экономические зоны. В производстве одежды свойственно использование около трети импортных промежуточных товаров для производства экспортных товаров. Менее глобальный характер имеют цепочки добавленной стоимости в добывающих отраслях, сфере телекоммуникаций, финансов и прочих услуг, поскольку в этих сферах необходимость иностранного сырья, компонентов или оборудования существенно ниже (рис. 10).

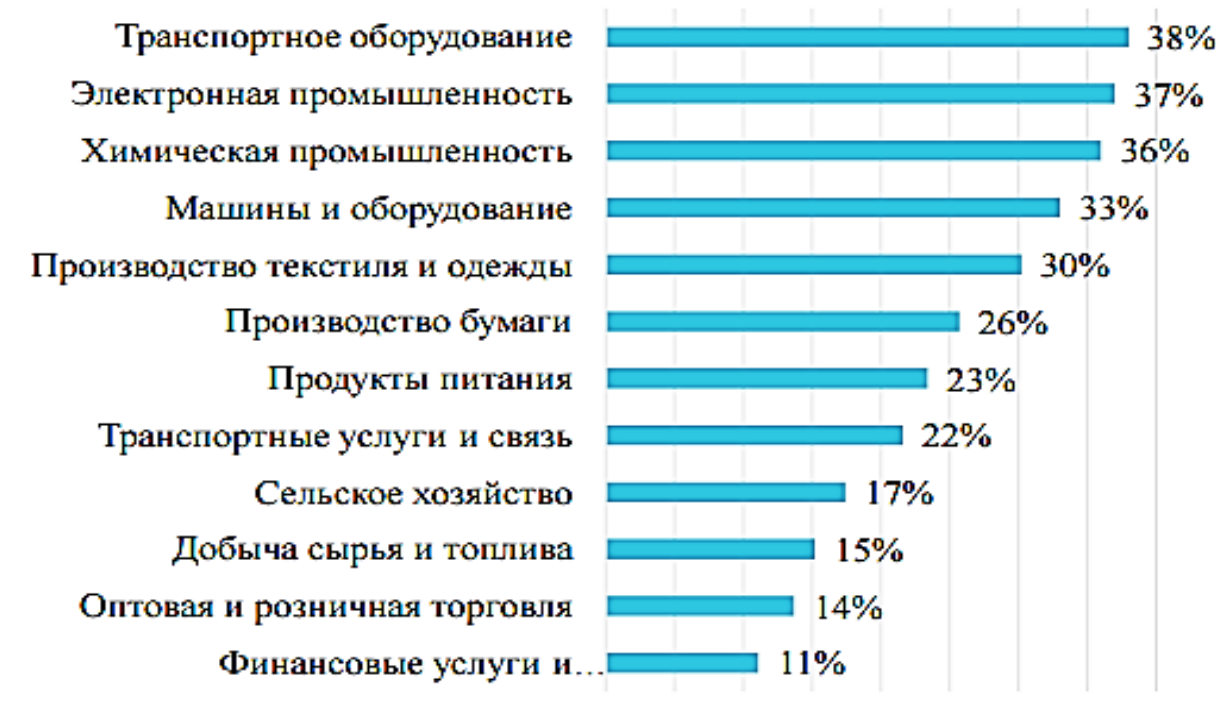

$0 \% 5 \% 10 \% 15 \% 20 \% 25 \% 30 \% 35 \% 40 \%$

Рис. 2. Доля иностранной добавленной стоимости в валовом экспорте различных отраслей промышленности и видов услуг в 2009 г. [2]

По статистике в мировой торговле доля промежуточной продукции превышает долю конечной продукции, а также долю инвестиционных товаров вместе взятых. Это говорит о том, что именно такой тип отношений, закрепляющий неравенство, неэквивалентный обмен, характерен и является ведущей чертой свойства современного мирового рынка. Источником прибавочной стоимости является живой труд, а не капитал сам по себе. 


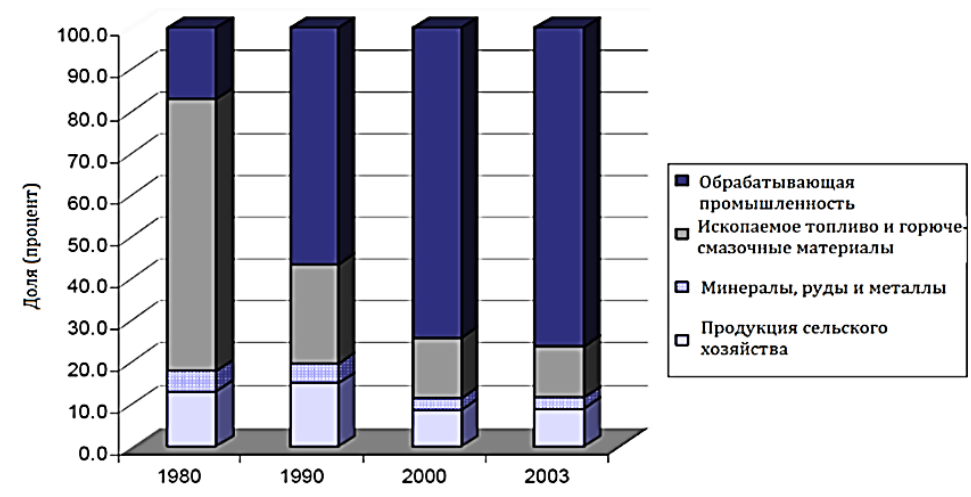

Структура товарного экспорта стран с низкими и средними доходами в страны с высокими доходами

Источник: Blecker R. \& Razami A. Developing Country Exports of Manufactures: Moving Up the Ladder to Escape the Fallacy of Composition? // American University, Department of Economics, WP 2006-06, p. 45

Рис. 3. Структура товарного экспорта стран с низкими и средними доходами, в страны с высокими доходами [6]

На рисунке 11 выше можно отследить тенденцию изменения динамики роста экспорта из развивающихся стран в развитые страны. В 1980 г. структура экспорта была такова, что только 20\% занимала продукция промышленного производства, остальное это сырье и сельскохозяйственная продукция. Затем наступает этап индустриализации нескольких развивающихся стран, прежде всего Китая. По данным на 2003г. ситуация становится прямо противоположной: значительную часть занимает продукция обрабатывающей промышленности, а только $20 \%$ занимает сырье и сельское хозяйство. Результатом таких изменений стала колоссальная урбанизация во многих странах, в частности в Китае порядка трехсот миллионов крестьян стали горожанами.

За все это время произошло шоковое расширение мировой рабочей силы. За 1990-е годы 1,47 млрд рабочих из Китая, Индии и бывшего СССР вступило в мировой капиталистический рынок труда. Со временем это количество увеличилось. На сегодняшний день по оценкам Международной Организации Труда число рабочих превысило 3 млрд. человек. Никогда в истории не было такого мощного индустриального промышленного рабочего класса. Индустриализация развивающихся стран происходила на основе трудозатратных традиционных технологий. Число рабочих тогда превысило число крестьян, работающих на основе ручного труда. По оценкам экономистов в мире сейчас насчитывается 
2 млрд крестьянского населения, которые заняты ручным трудом в сельском хозяйстве. Также по их расчетам продукцию, которую эти крестьяне производят, могли бы производить примерно 200 млн человек фермерского населения, если бы они были оснащены современным капиталом и современными аграрными технологиями. Другими словами, 1,8 млрд человек могли бы перейти из статуса крестьян и перейти в рабочий индустриальный класс. Исторически сложилось так, что именно за счет вовлечения бывших крестьян в производство, капитализм стал преодолевать свои глобальные кризисы.

Между тем, происходит перераспределение прибавочной стоимости между группировками капиталистов в пользу тех группировок, капитал которых мощнее предыдущих. В результате получается, что продукция отраслей, где капиталвооруженность выше, продается по стоимости выше и получает избыток стоимости. А продукция, произведенная в отраслях, где капиталы слабее, а доля труда выше, продается ниже реальной стоимости.

Суть периферийных экономик в том, что они значительную долю своего фонда трудовой стоимости безвозмездно передают странам центра.

Это проявляется:

- в вывозе капитала (за 2012 год из России чистый отток частного капитала превысил \$ 210 млрд);

- в занижении национальной валюты, которая является важным механизмом передачи стоимости развитым странам;

- в занижении стоимости рабочей силы (в Китае стоимость труда рабочего в 10 раз меньше труда рабочего из США, но при этом больше стоимости рабочей силы в России в 1,5 раза).

Все вышеперечисленные пункты являются ценой за доступ на рынки западных стран. Многие страны вынуждены платить эту цену [5].

\section{Заключение}

Важным элементом мировой экономики, на протяжении многих лет, остаются глобальные цепочки добавленной стоимости. Они дают большое развитие международному производству благодаря вовлечению новых стран в торговое 
сотрудничество и распределению мощностей предприятий для экономически выгодных решений. Начиная с 70-х годов XX века, и по настоящее время, появление глобальных цепочек стоимости играет важную роль в сокращении издержек на крупных производственных предприятиях. Первым использовала в своей практике международный аутсорсинг США, тем самым став отправной точкой в истории формирования ГЦС для многих западных компаний.

Для каждого вида отрасли ГЦС носят неоднородный характер. Так, например, наиболее глобальный характер носят транспортные отрасли и электронная промышленность. Причиной, по которой многие страны с периферийной экономикой становятся участниками глобальных цепочек стоимости, является возможность выйти на рынки развитых капиталистических стран. Это становится реальным только при вступлении в сотрудничество с крупными транснациональными корпорациями, которое подразумевает под собой выполнение всех условий сотрудничества и предложение более качественного и дешевого выполнения всех обязательств.

\section{Сиисок литературы}

1. Анализ глобальных цепочек в моделях международной торговли: Учебник / Игнатенко, В.В. Идрисова, Ю.О. Литвинова. - 2017.

2. UNICTADSTART (UNICTAD Foreign direct investment database) информ. аналит. материалы. - 2008 [Электронный ресурс]. - Режим доступа: http://unctad.org/en/Docs/iteiit20075_en.pdf

3. Фефелов Р.Е. Зарубежный опыт использования аутсорсинга во внешнеэкономической деятельности корпораций // Экономический журнал. - 2014. - №1 - С. 4-26.

4. Дзарасов Р.С. Развитие в современном мире: Возможен ли национально ориентированный капитализм: Книга. - 1-е изд. - ЦЭМИ РАН, 2014. - С. 4-28.

5. OECD. Interconnected Economies and WTO. Database \& report. -2009.

6. The Global Value Chains Initiative [Электронный ресурс]. - Режим доступа: https://globalvaluechains.org/concept-tools 


\section{References}

1. The analysis of global chains in models of international trade: Text-book / Ignatenko, V.V. Idrisova, Yu.O. Litvinova. - 2017.

2. UNICTADSTART (UNICTAD Foreign direct investment database) inform. anolyte. materials. - 2008 [Electronic resource]. - Access mode: http://unctad.org/en/Docs/iteiit20075_en.pdf

3. Fefelov R.E. Foreign experience of use of outsourcing in foreign economic activity of corporations // The economic magazine. - 2014. - №1 - - P. 4-26.

4. Dzarasov R.S. Development in the modern world: Whether national focused capitalism is possible: Book. - The 1st edition. - TsEMI RAS, 2014. - P. 4-28.

5. OECD. Interconnected Economies and WTO. Database \& report. - 2009.

6. The Global Value Chains Initiative [Электронный ресурс]. - Режим доступа: https://globalvaluechains.org/concept-tools

Эпов Иван Сергеевич - магистрант ФГБОУ ВО «Российский экономический университет им. Г.В. Плеханова», Россия, Москва.

Epov Ivan Sergeevich - graduate student at the Plekhanov Russian University of Economics, Russia, Moscow. 